\title{
Coping with complications
}

\author{
Rose M Carter QC ${ }^{1}$, Paul C Adams MD FRCPC ${ }^{2}$, Editor-in-Chief
}

$\mathrm{R}$ ose M Carter is a partner with Bennett Jones LLP in Edmonton, Alberta. Her area of interest is representing physicians in civil lawsuits involving allegations of medical negligence, patient complaints to the College of Physicians and Surgeons of Alberta and other related administrative and civil procedure matters. Other practice areas include general litigation, commercial litigation and participation in public inquiries. To complement her practice, Rose is an adjunct professor of the Faculty of Medicine and Dentistry at the University of Alberta. She also lectures frequently at local, national and international seminars and meetings for physicians, residents and medical students regarding medical negligence and bioethics issues. Ms Carter was recently a guest speaker at the 2007 Canadian Digestive Diseases Week held in Banff, Alberta and organized by the Canadian Association of Gastroenterologists.

PA: As gastroenterologists, we are often performing endoscopic procedures that can result in perforation of the bowel and other untoward effects. When a serious complication occurs in a patient, what is the best strategy for dealing with the patient and his or her family?

RC: Always have at the forefront of your mind that a complication can arise. That way when, for example, a bowel perforation occurs, there is no delay or denial on the part of the gastroen-

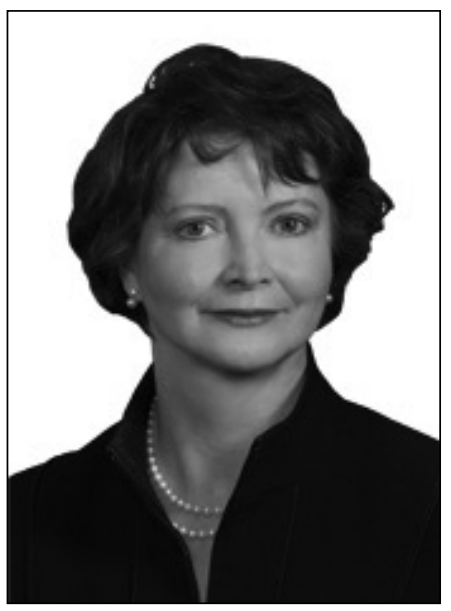

Rose M Carter is a partner with Bennett Jones LLP in Edmonton, Alberta. Her area of interest is representing physicians in civil lawsuits involving allegations of medical negligence, patient complaints to the College of Physicians and Surgeons of Alberta and other related administrative and civil procedure matters
4. Assure the patient, with his or her consent, that you will talk to his or her family as soon as you have made sure that the immediate medical problems are being dealt with and that you will keep the family apprised.

5. As soon as possible, seek out a family member and explain briefly what has occurred, what steps you are taking, and assure them your principle concern at the moment is their loved one and that you will be back to report once the patient's medical care is in hand.

6. Make yourself available to the patient and family throughout the recovery period.

PA: If you are involved in a car accident, it seems that it is often recommended to have minimal discussion with the other party about fault or events. Is this similar after an endoscopic complication?

RC: Yes. There are many reasons for a complication to occur and often it is not until some time after the event that all the facts become known. Therefore, it is a disservice not only to the gastroenterologist but also to the patient to jump to conclusions. The placing of fault or speaking beyond what the gastroenterologist knows to have been the occurrence or been the unfolding of events should be avoided.

PA: Most gastroenterologists will discuss the potential for these complications to occur just before the procedure. Do you advocate quoting actual numbers and what could happen if a complication occurs? Does every patient receive the same message?

\footnotetext{
${ }^{1}$ Bennet Jones LLP, Edmonton, Alberta; ${ }^{2}$ London Health Sciences Centre, London, Ontario

Correspondence and reprints: Rose M Carter QC, Bennett Jones LLP, 1000 ATCO Centre, 10035 105th Street, Edmonton, Alberta T5J 3T2. Telephone 780-421-8133, fax 780-421-7951, e-mail MCKAY@bennettjones.ca

Received for publication April 10, 2007. Accepted April 10, 2007
} 
RC: For material risks, for example, death and perforation, if gastroenterologists are going to cite numbers, those numbers, where possible, ought to be supported by peer review literature. In advising patients of complications, it is important to stress what may occur if complications arise. For example, a bowel perforation will likely require a laparotomy and, depending on the seriousness of the injury and comorbidities, the patient may spend some time in the intensive care unit and will certainly be in the hospital for some period of time. I suggest that gastroenterologists develop a standard practice for explaining benefits and risks of each procedure they undertake. Consistency in giving the same message to each patient is important.

PA: How does the doctor respond to the question: "How did this happen?"

RC: It depends on when this question is asked. If it is immediately upon realizing a complication has occurred, the physician may not have all of the information. All that a physician may be able to tell the patient at that point is that all of the information is not presently available but the patient will be told as soon as the information becomes available. Having advised the patient prior to the procedure that a complication of this nature can occur and how it can occur, the patient need only be reminded of that discussion, because the foundation has been set.

PA: It seems like the message is 'don't run from the scene of the accident'.
RC: Absolutely. The most important thing for the physician to convey upon learning of a complication is to make it clear to the patient that they are not being abandoned or being blamed for the complication. The focus should be placed on dealing with the complication with the best medical help available. This is the test of the physician as a professional. It is easy when things are going well. The consummate professional deals with complications in a forthright, compassionate and intelligent fashion.

All procedures carry risks. It is the responsibility of the patient to advise the gastroenterologist of any risks or comorbidities of which the gastroenterologist may not be aware. It is the gastroenterologist's responsibility to explain the risks and benefits of each procedure offered. It may be that the patient and the gastroenterologist decide, in the face of comorbidities, that performing a certain procedure is not in the patient's best interests. If so, that should be documented. A significant advantage of telling the patient of procedural risks is that if a risk materializes, a gastroenterologist is able to say to the patient, "Remember we discussed before the procedure what could go wrong with the procedure. Unfortunately, one of the risks we discussed (a bowel perforation) has occurred and this is how we are going to deal with it." Figuratively speaking, the gastroenterologist and the patient should walk into any procedure hand-in-hand with both understanding the benefits and risks of the proposed procedure. 


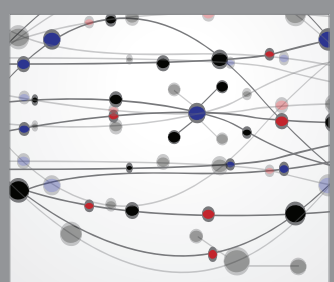

The Scientific World Journal
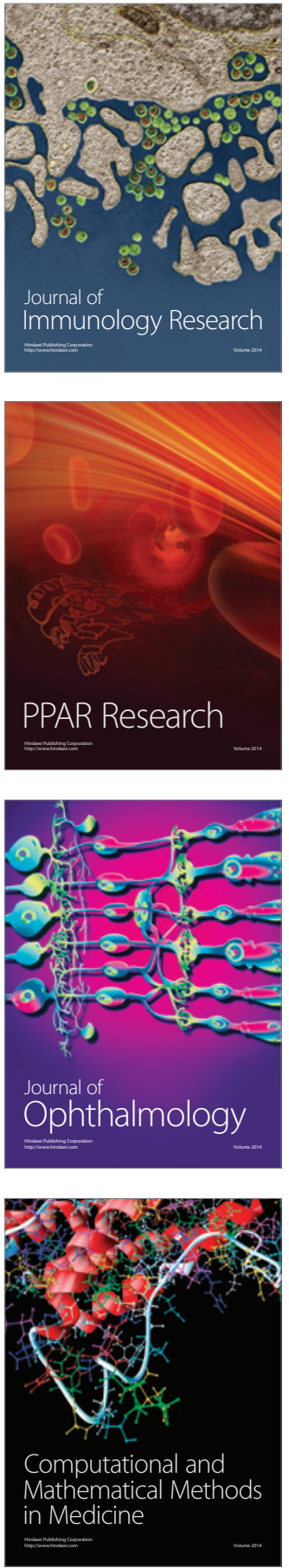

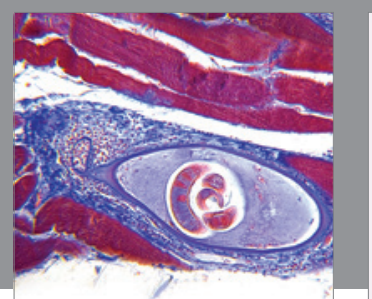

Gastroenterology Research and Practice

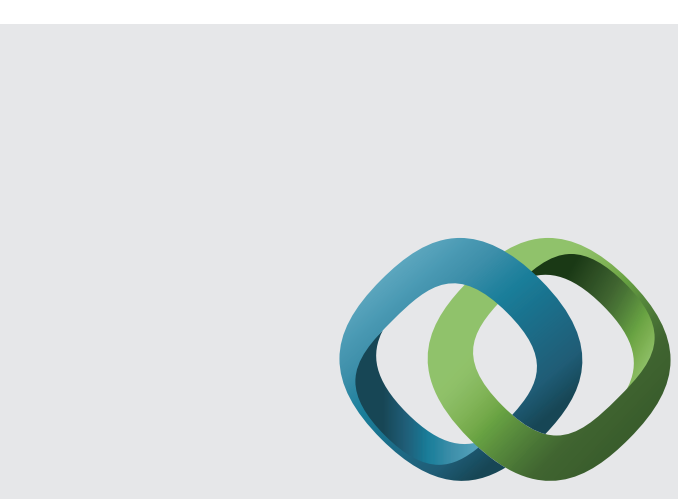

\section{Hindawi}

Submit your manuscripts at

http://www.hindawi.com
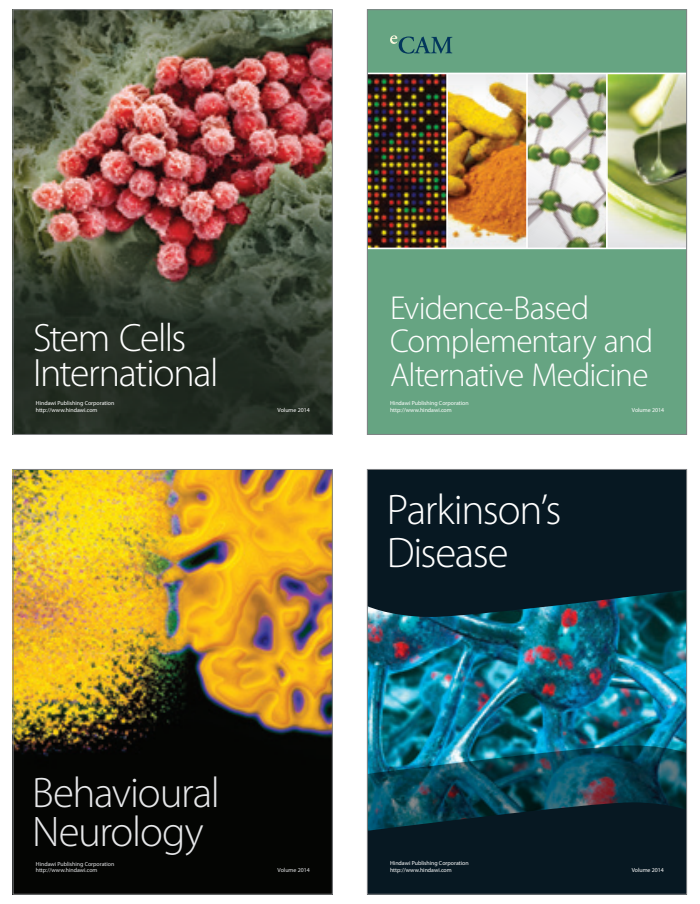
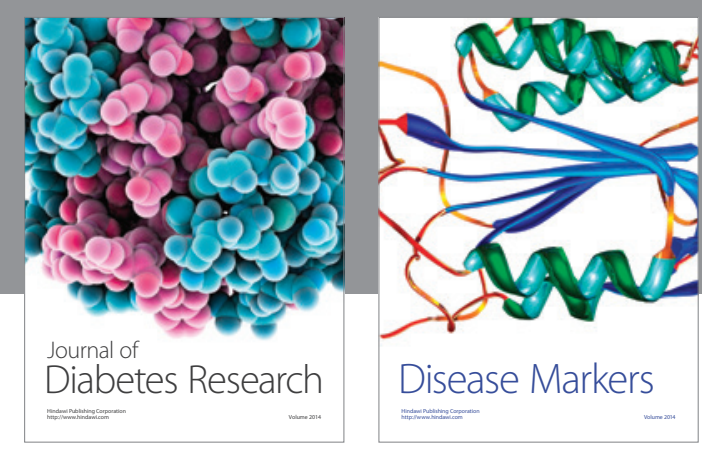

Disease Markers
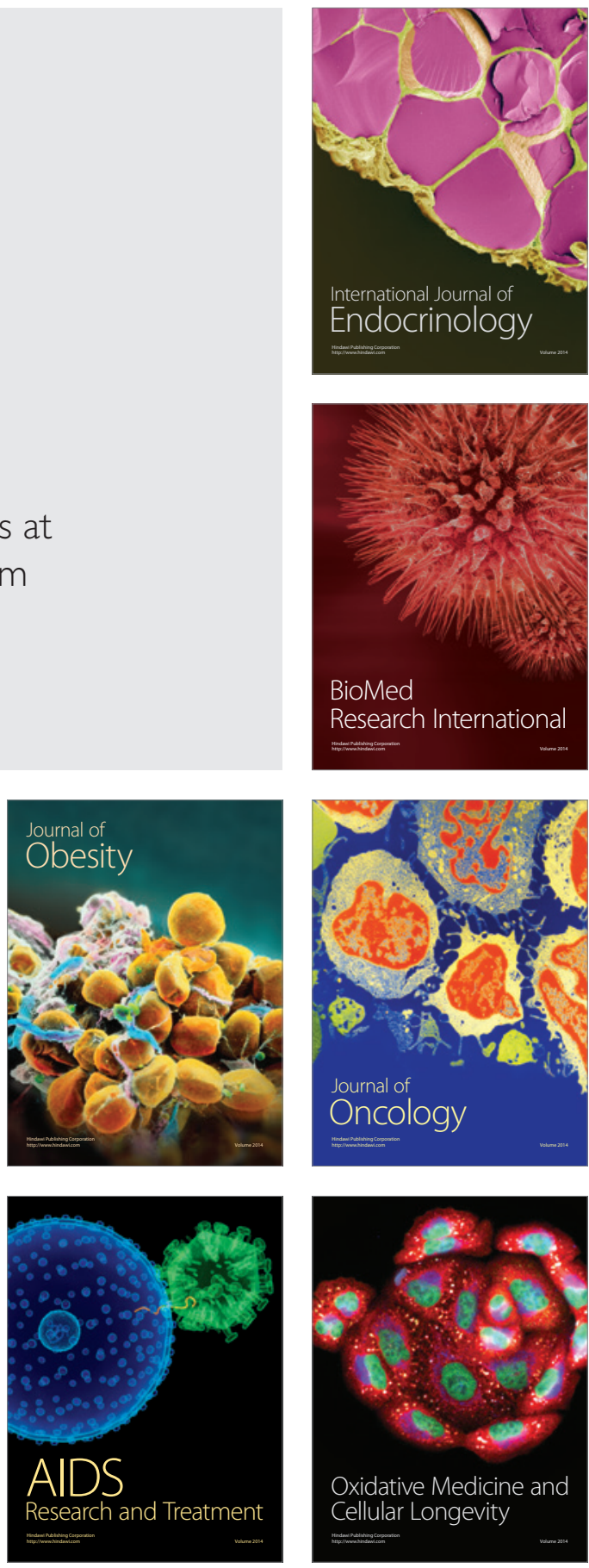